\title{
TERAPIAS ONCOLÍTICAS VIRAIS PARA O TRATAMENTO DO GLIOBLASTOMA MULTIFORME: REVISÃO SISTEMÁTICA
}

\author{
Maria Rebeca Feitosa Ribeiro', Lucas Tavares Cruz de Albuquerque ${ }^{1}$, Daianny Mesquita Ponte ${ }^{1}$, Leyde \\ Jenifer Dias Uchôa ${ }^{1}$, Caroline Pereira Modesto ${ }^{1}$, Giovany Michely Pinto da Cruz².
}

\begin{abstract}
Introdução: Glioblastoma Multiforme (GBM) é o tumor cerebral mais frequente em adultos e possui uma alta taxa de mortalidade. A média de sobrevida dos pacientes com esse tipo de câncer é de 12 meses. Além disso, ele costuma apresentar resistência aos tratamentos convencionais. Desse modo, estão sendo investigados tratamentos auxiliares para o GBM, incluindo o uso de cepas modificadas de vírus, dentre os quais estão o Vírus da Zika (ZIKV) e o Vírus do Sarampo (MV). Objetivos: Analisar duas terapias oncolíticas virais auxiliares no combate ao GBM. Métodos: Foi feita uma revisão sistemática sem metanálise, cujos artigos foram buscados nas bases de dados eletrônicas PubMed e SciELO. Os critérios de inclusão foram: artigos com o idioma em inglês e português, publicados entre 2013 e 2018, cujos estudos fossem do tipo ensaio clínico, com não humanos sendo a população em estudo. Foram encontrados 21 artigos, porém apenas 5 foram selecionados, pois cumpriam os critérios de inclusão. O protocolo utilizado foi o PRISMA. Resultados: Com a análise dos estudos, podemos observar que o GBM possui células iniciadoras de tumor (GSCs), que aumentam a malignidade tumoral e a resistência terapêutica, e em decorrência disso e por ter alta chance de recorrência, várias terapias estão sendo testadas para auxiliar no tratamento do GBM, incluindo a terapia oncolítica viral. Os mecanismos dessas terapias ainda não são bem conhecidos, mas observou-se que o ZIKV atuou induzindo a síntese de digoxina nas células tumorais, a qual inibe a bomba sódio-potássio e ativa a Caspase-3, que gera apoptose, liberando espécies reativas de oxigênio e ocasionando a morte celular, de forma a alterar a tradução do DNA, afetando a síntese proteica. Já o vírus do sarampo atuou produzindo um efeito citotóxico sobre as células do GBM, gerando uma inibição do crescimento do tumor. A partir da análise dos estudos, constatamos que os benefícios dessas terapias são o fato de possuírem seletividade pelas células tumorais e de aumentarem a sobrevida. Conclusão: Apesar de terem sido analisados vírus modificados de diferentes cepas, concluimos que mais estudos precisam ser realizados com o intuito de conhecer melhor os efeitos do uso desse tipo de terapia, podendo até ser estudada a combinação do ZIKV com o MV, pois percebemos que ambos os vírus atuam interferindo nas GSCs, porém em receptores diferentes. Isso somado à quimioterapia e à ressecção cirúrgia pode ter um efeito mais eficiente no combate ao GBM.
\end{abstract}

Palavras-chave: Glioblastoma (Glioblastoma). Zika (Zika). Sarampo (Measles).

\footnotetext{
${ }^{1}$ Acadêmicos de Medicina da Faculdade de Medicina Estácio de Juazeiro do Norte.

2 Doutor em Ciências pelo Programa de Neurologia/ Neurociências da Universidade Federal de São Paulo (UNIFESP 2012), Mestre em Ciências Fisiológicas pela Universidade Estadual do Ceará (UECE - 2001), graduado como CirurgiãoDentista pela Universidade Federal do Ceará (UFC - 1995). Professor Assistente III da Faculdade de Medicina Estácio de Juazeiro do Norte.
}

Autor correspondente: rebecafeitosaribeiro@gmail.com.

37 Id on Line Rev. Mult. Psic. V.12, N. 40. 2018 - ISSN 1981-1179 EDIÇÃO ESPECIAL: I CURSO DE ONCOLOGIA DO CARIRI / II JORNADA DE PESQUISA QUANTI-QUALITATIVA EM ONCOLOGIA. JUAZEIRO DO NORTE, 05 A 10 DE MARÇO DE 2018. Edição eletrônica em http://idonline.emnuvens.com.br/id 